\title{
THE USAGE OF POSITAL CANOPEN AGS15 INCLINOMETERS FOR DIAGNOSTIC MONITORING OF SLENDER STRUCTURES
}

\author{
Ireneusz Wyczałek, Artur Plichta, Michał Wyczałek \\ Institute of Civil Engineering \\ Poznan University of Technology \\ Poznan, Poland
}

\begin{abstract}
This paper concerns the possibility of using AGS15 capacitive inclinometers in the geodetic monitoring of slender structures. The basics of geometric monitoring have been introduced, and the features of inclinometers that can be used in these studies have been described. Main expectations towards them have been formulated. Three tests were conducted: (1) a few days' stability test of readings, (2) the test of inclinations controlled tachimetrically and (3) continuous survey of a physical object. It has been found that in order to obtain satisfactory results it is necessary to correct the readings due to the drift and the effect of temperature. The works conducted as part of described project work are not capable of identifying those indicators. To achieve them there were designed the system that support the acquisition and processing of the measurement and also the collection and transmission of results. In the conclusions authors stated that inclinometers AGS15 can be suitable for monitoring, but the works aimed at improving their performance should be undertaken.
\end{abstract}

Keywords: inclinometer, diagnostic surveys, usability test

\section{Introduction}

Geometric diagnosis of engineering constructions is one of the rapidly developing fields of structural monitoring. The main aim of monitoring is (quasi-) continuous tracking of selected geometric features of an object in order to determine the extent of its changes over the time and their relation to the factors that affect these changes. Collected information is processed and analyzed to detect any threats caused by hazards as well as to give possible early warnings. From scientific point of view the relationships between the structure and the various factors that influence them are 
analyzed. Obtained results are confronted with theoretical models in order to assess their accuracy, and their correspondence with the expected results.

Monitoring is carried out mainly by using specialized tools and scientific software. These systems are quite expensive, and - they are designed and implemented in a way focused on a specific tasks (related to the specific hardware and its planned usage). As the result one can get important but quite costly information, some of them are necessary to ensure protection of an object and comfort of its use. The complexity of operating such systems also requires properly trained staff for supervising its usage. Because of the growth of necessity for good geometrical monitoring it is necessary to make it universal in terms of availability (price), versatility and easy use. It is therefore important to create and test some new sensors and try to implement them for structural monitoring systems. These sensors, in addition to surveying instruments, could be electronic or hydrostatic levels, inclinometers, extensometers, feelers, accelerators, and the other ones.

Among the commercially available high precision instruments (on the base of declared accuracy) are AGS CANopen inclinometers made by POSITAL. Their analysis is presented in this paper. It was assumed that in case of the positive results of carried tests they could be used to study verticality of the towers, mobile poles or other high objects. Its real use is expected during assembly of the tower and during its operation - for example during an evaluation of its behavior in bad weather conditions (strong wind, ice, extreme temperatures). Here we describe the study object, the range of investigations and the conclusions drawn from them.

\section{The use of inclinometers in the buildings diagnosis}

Electronic inclinometers are used in the diagnosis of engineering objects nothing less than since the beginning of the twenty-first century. A particular field of their use relates to objects in seismic (Sherman et al., 2011) and volcanic (Arnoso et al., 2012) areas, mining areas (Álvarez-Vigil et al., 2010; Milev et al., 2013), dams (Yun Wu \& Yijin Wu, 2013), tunneling (So-Keul et al., 2010) and bridges (Hou et al., 2005).

Among other, Burdet and Zanella (2002) used inclinometers, along with other devices (thermocouples, hydrostatic leveling instruments), to assess the long-term deflections of spans of Riddes bridges in Switzerland. The result of this survey led to the conclusion that the static bridge is strongly influenced by thermal factors. The monitoring methods was applied again to short-term observation of structural elements of the Swiss Mentue bridge (Burdet \& Zanella, 2000). To achieve the assumptions there were used a set of five high-definition inclinometers (precision $1 \mathrm{~mm} / \mathrm{km}$ ) installed on the central span of the bridge, and next two - at the ends of it. Here, also, the measurement results were compared with observations of inclination obtained by hydrostatic leveling, gaining similar results. Inclinometers were also used to study the behavior of the wind turbine pillars due to environmental conditions changes. Rohrmann et al. (2010) evaluated the dynamics of these process over the Multibrid M5000 wind turbine during its work. The normal load and the bending moment were measured by the set of accelerometers and inclinometers mounted on six different levels. In both these cases, as in many other further analyses, are the inclination angles of the structure or its part. Such approach have been also used in the studies described below. 


\section{The subject of research}

\subsection{The relationship between the tilt angle and linear value of inclination}

The main task of this paper is to assess the technical condition of the slender structures - towers or masts used in mobile telephony or chimneys. The aim of the survey is to determine the derogation from the vertical axis. Deformations of the slender structures are commonly referred as a vector offset from its axis at selected level in relation to the axis of the base. Inclination size is given in the units of distance - in the directions of the axes of co-ordinate system and the direction of maximum deflection. The use of inclinometer leads to the results given in angular units, what requires the results to be converted to linear form. Using the appropriate algorithm is dependent on the adopted model of deflection. Figure 1 shows three examples of solutions assuming: a) a joint at the base of the rigid object, b) a joint at given height (in this case - at half, two thirds and three fourths of the height of the object, respectively), c) the flexibility of the object, without joints.

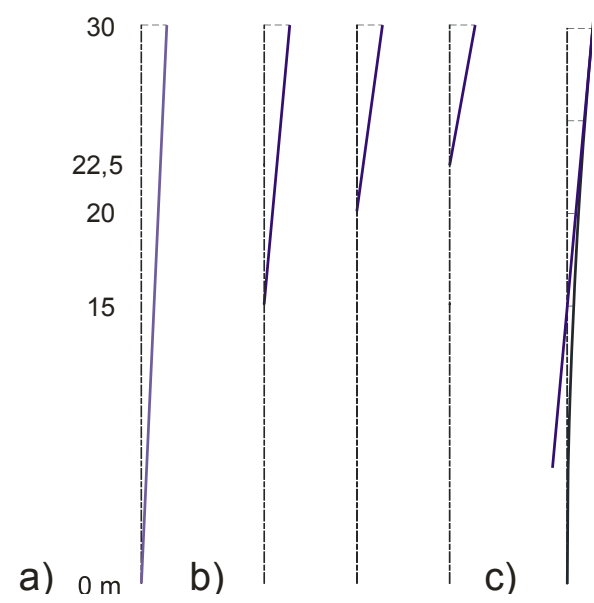

Fig. 1. Selected models of construction behavior: a) the rigid structure with the joint at the base, b) the object with the joint at a part of the height, c) flexible object, without joints.

For description of the curvature of the object changing in a very small extent (version c) there is no need for complex mathematical apparatus. This may be a quadratic equation, such as:

$$
u=\mathrm{a} \cdot \mathrm{w}^{2}
$$

where $u$ is the deviation, and $w$ - the height at which the measurement is made. The derivative calculated at $w_{0}$ is equal to the tangent of the angle at this point:

$$
\mathrm{m}=\frac{\partial \mathrm{u}}{\partial \mathrm{w}}\left(w_{0}\right)=2 a \cdot w_{0}
$$

The angle calculated this way has a value close to the angle of the object considered as a rigid body, with joint around the middle of its height. The model presented above indicates only the problem and requires the implementation of experimental research on a particular subject. In order to convert the measured angle of inclination for the linear value it is required to solve the inverse problem: 
calculating $\mathrm{a}=\mathrm{m} / 2 \mathrm{w}_{0}$, and then $u$ using the formula (1). This way one can track the (linear) deflections of the object on its selected levels.

\subsection{Advantages and disadvantages of using inclinometer for continuous measurement of inclination}

The advantages of the proposed solution include:

+ One-time installation of the device (one or more) on the object,

+ Continuous monitoring, recording functions, warnings and possibility of calibration,

+ Possibility of remote control for multiple objects with the monitoring center.

The disadvantage or difficulty with this approach might be:

- Unit cost (usually it is impossible to replace),

- Power supply (supply the power or long-life battery),

- The survey depends on external factors (the correction on display).

To achieve the desired effect, it is considered as necessary desire to purchase inexpensive sensor, its instrumentation (counter, power supply, readings transmitter), calibration and control through custom software.

\subsection{AGS inclinometer by POSITAL/FRABA}

The selection of AGS inclinometer is justified not only by its relatively low price and relatively high accuracy performance (catalog), but also other useful features such as a plurality of output formats, the ability to change the parameters of its work from the external device and the ability to calibrate. These devices are made in three different measured gradients in terms of coverage. Other interesting features are listed in the Table 1 (Wyczałek et al., 2013).

Table 1. Specification of family of inclinometers AGS

\begin{tabular}{|l|l|l|l|}
\hline Model & AGS 5 & AGS 15 & AGS 30 \\
\hline Measuring range & $+/-5^{\circ}$ & $+/-15^{\circ}$ & $+/-30^{\circ}$ \\
\hline Resolution & $0.001^{\circ}$ & $0,001^{\circ}$ & $0,005^{\circ}$ \\
\hline Accuracy $\left(\mathrm{T}=0{ }^{\circ} \mathrm{C} . .+55^{\circ} \mathrm{C}\right)$ & $0,01^{\circ}$ & $0,01^{\circ}$ & $0,02^{\circ}$ \\
\hline Inclination angle in $\mathrm{x}$ and y & $+/-15^{\circ}$ & $+/-40^{\circ}$ & $+/-60^{\circ}$ \\
\hline Damping period $0^{\circ}->5^{\circ}$ & typical 1s 10\%, 2s 1\%, 3s 0,1\% \\
\hline Interface & Transceiver according ISO 11898, \\
\hline & galvanically isolated by opto-couplers \\
\hline Transmission rate & max. 1 MBaud \\
\hline Device addressing & Adjustable by rotary switches in connection cap \\
\hline Supply voltage $(2)$ & $10-30 \mathrm{~V}$ DC (absolute limits) \\
\hline Current consumption & max. 230 mA with 10 V DC, max. 100 mA with 24 V DC \\
\hline Power consumption & max. 2.2 Watts \\
\hline EMC & Emitted interference: EN 61000-6-4 \\
\hline & Noise immunity: EN 61000-6-3 \\
\hline Electrical lifetime & $>10^{5} \mathrm{~h}$ \\
\hline
\end{tabular}

The accuracy of $0,01^{\circ}\left(40^{\prime \prime}\right)$ corresponds to the deflection of $1.7 \mathrm{~mm}$ for the 10 meter-high object. At the same time the manufacturer uses the factor of precision, which is 10 times higher than the guaranteed accuracy. In some way the accuracy 
can be increased. Noteworthy is also high speed of sensor stabilization (up to 2 seconds) and resistance to short-term oscillations of small amplitude (up to $2.5 \mathrm{~mm}$ ).

\subsection{The design of interface}

In order to facilitate research, and also to enable more efficient operation it was designed and also performed the sensors instrumentation (Fig. 2). It includes modules of the read-counter (CZ\#) as well as local base stations (LSB\#) for the collection and transmission of readings from a few/several sensors, not only inclinometers, but also weather stations or other devices. The measurement results are sent to the center of the data collection and processing (GPD Center), which task is to analyze the observations and warnings about exceeding the limit states (Wyczałek et al., 2013).

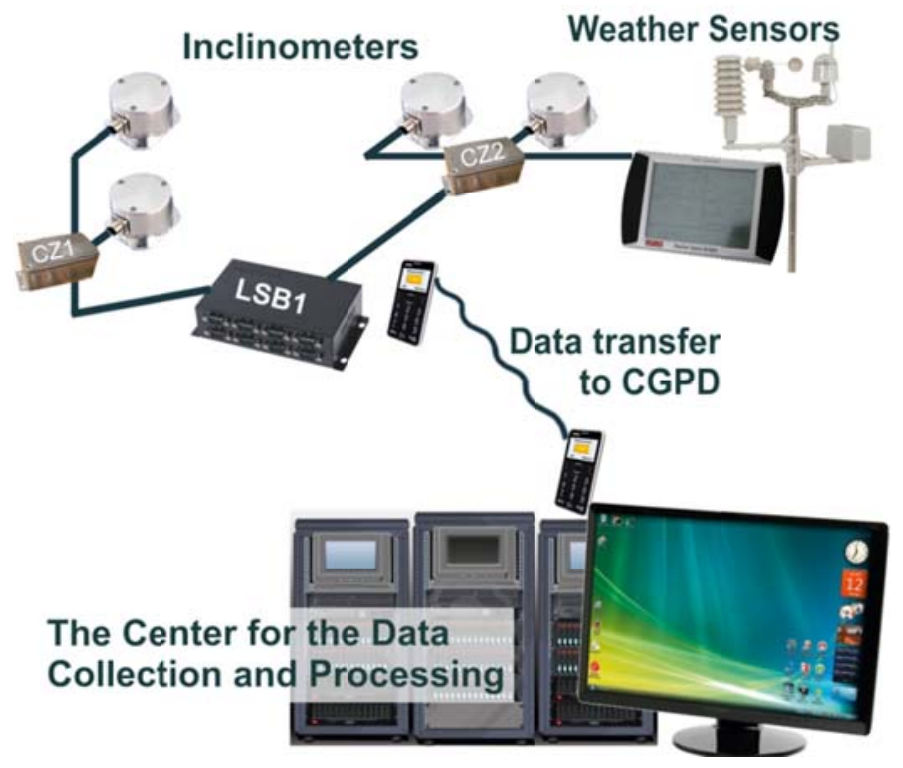

Fig. 2. The idea of a system for recording and transmission of data (Wyczałek et al., 2013).

The set of devices discussed above is currently under installation and testing. In order not to hinder the research, two inclinometer AGS15 were evaluated using custom, simple interface - mobile PC and a HyperTerminal software.

\section{The research}

\subsection{Laboratory tests}

In the Department of Geodesy at Poznan University of Technology there were carried out several tests of both previously purchased AGS15 inclinometers. The study aimed at determining the real possibilities of the precision of these devices, without taking into account external factors. There were performed three tests:

1) repeatability and readings dispersion test - stationary sensors,

2) repeatability and readings dispersion test - sensors tilted for the specified value,

3) the practical test - mobile pole deflection monitoring. 
The first test consisted of simultaneously registration the readings in interval of 2 seconds for two stationary inclinometers. As a result of a multi-day (178-hour) observations there were obtained numerous samples of the data grouped in four blocks (two sensors on the two axes). Figure 3 illustrates the obtained results for one of the devices. Dark lines (thicker ones) indicate the average values for following 15 readings that gives the results for 30 -second intervals. The spread of these results does not exceed $0,002^{\circ}$ which presages quite well for the future. The graph shows that in the analyzed time an interval for the $X$ axis readings raised linearly from $0.020^{\circ}$ to $0.019^{\circ}$, and their equivalents for $Y$ axis steadily decreased its values from $0.011^{\circ}$ to $-0.011^{\circ}$. The readings are different from their counterparts for the second inclinometer, but their ranges are similar.

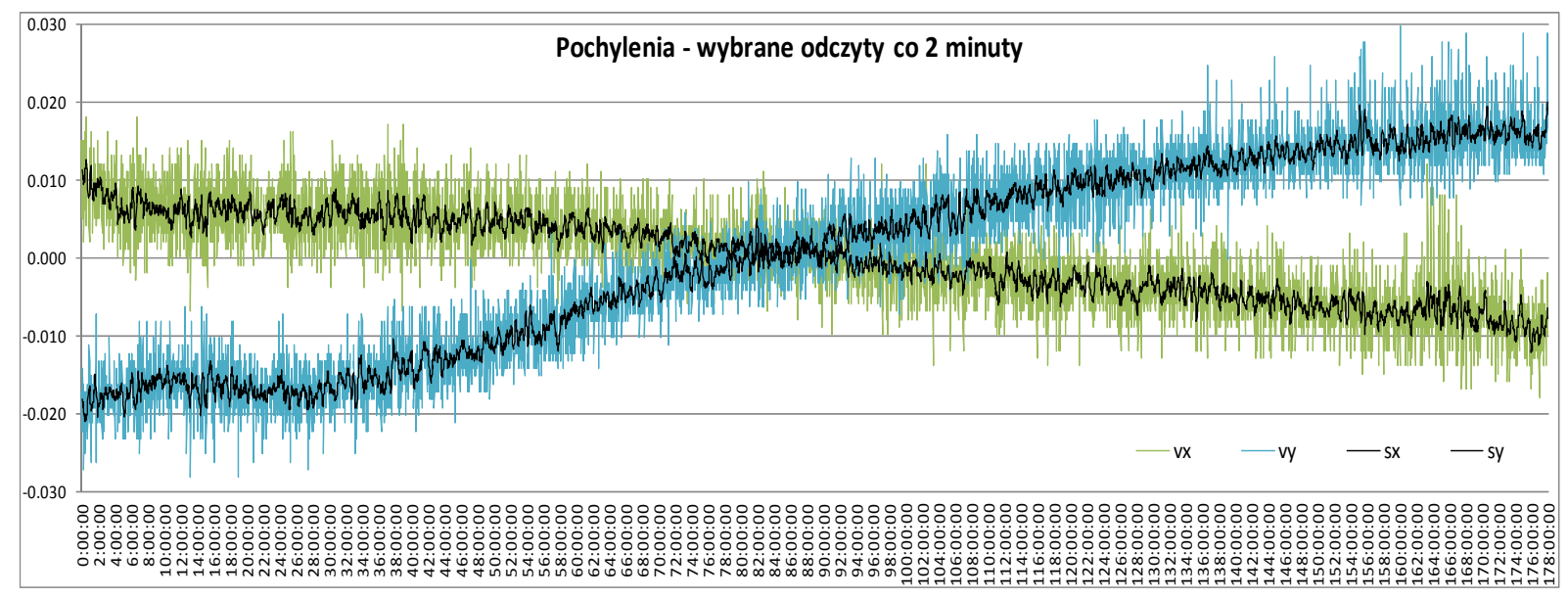

Fig. 3. The variability of AGS15 readings in one week test without changing the position (Wyczałek et al., 2013)

This characteristic does not correspond to conventional regression models, especially during the initial, approximately 36-hour time interval. Therefore we may conclude, that:

1) the device must be stabilized before the long-term measurements,

2) after the stabilization process the readings scatter is almost regular, so in case of short-term changes correction there could be used linear regression models.

There is also a problem with averaging the values. It was attempted to apply a median filter for different sample size that has to be averaged. Figure 4 shows the results of five such trials (for different time periods to see differences).

The central filter (groups of 15 readings) appears to give optimum results. Medians calculated for the every 5 readings improve dispersion of about $39 \%$, for 10 readings $-54 \%$, for $15-64 \%$, for $20-71 \%$ and for 25 readings $-73 \%$ better. The median filter calculated for the blocks of 15 reading should give satisfactory results - for a frequency of $10 \mathrm{~Hz}$ it corresponds to readings for every $1.5 \mathrm{sec}$. In practice the filter was modified by removing about $50 \%$ of the extreme readings in each block. In this case, the already 10 -reading blocks gave improvement of over $60 \%$. 

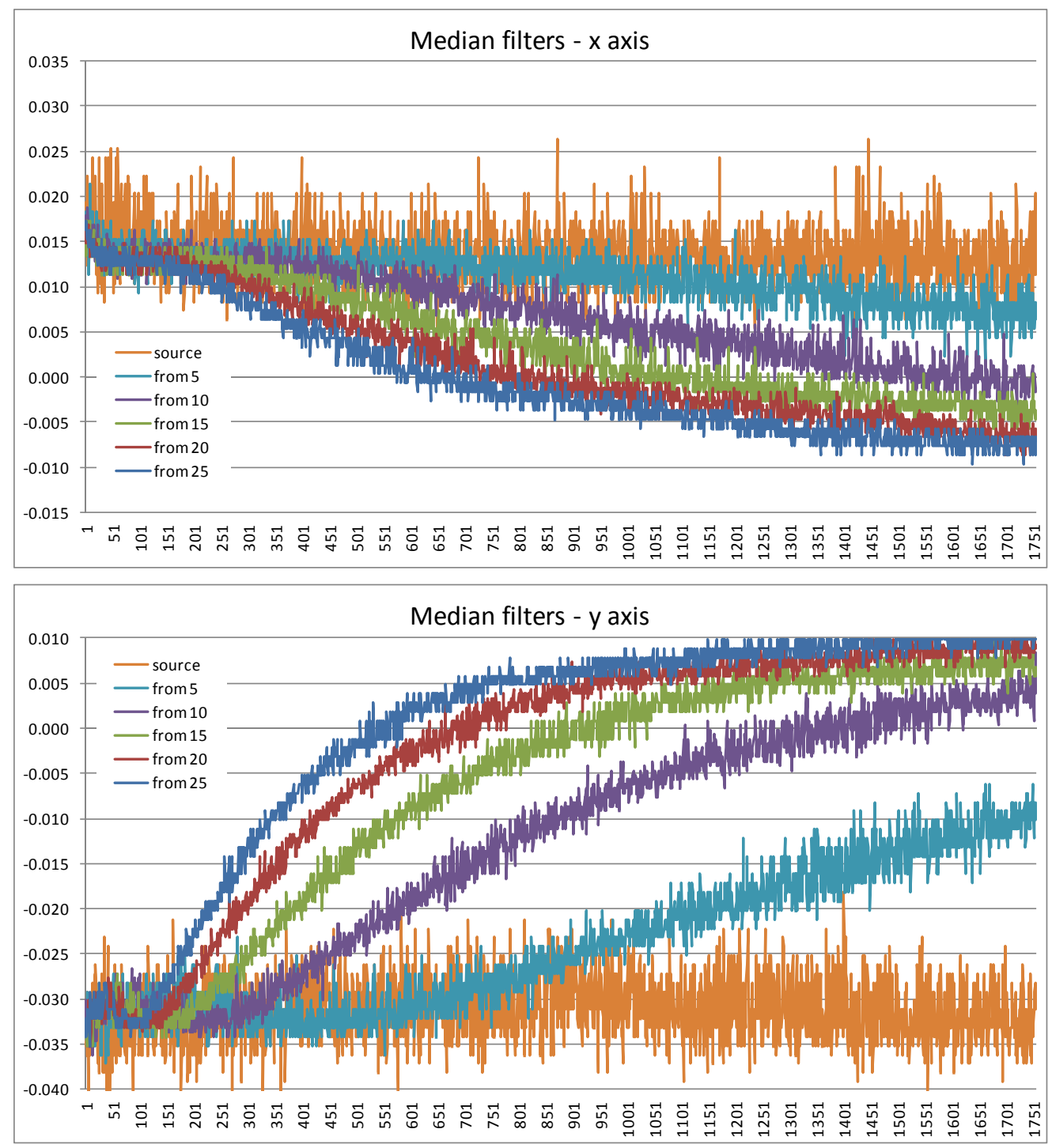

Fig. 4. Median filtering for selected group of inclinations readings

The second of these tests based on a comparison of deflection of the inclinometer in 4 selected sizes, which were measured in the same time by Leica TCRP 1201+ precision tachymeter, and aiming at two precise prismatic reflectors that were away at about $1.2 \mathrm{~m}$.

The accuracy of measurement of the inclination angle is $\pm 0.05^{\circ}\left(3^{\prime}\right)$. The graph (Figure 5) shows the spread of inclinometer readings for the maximum slope in five consecutive series of observations. The most interesting are the scatter dispersions from $\pm 0.012^{\circ}\left(45^{\prime \prime}\right)$ in the first series (the largest) to $\pm 0.006^{\circ}\left(22^{\prime \prime}\right)$ in a series number 3 . It is probably the result of more or less conducted stabilization process of the inclinometer. Apart from this it should be noted that both the spread and the difference between tacheometric surveying $\left( \pm 0.032^{\circ}\right)$ is smaller than the above specified error of that measurement.

Intermediate inclination measurements lasted half the time less, which reflects to significantly lower number of reads, and as a result - the greater error of estimation accuracy. Despite slight differences of mentioned above, they were omitted in further analyzes. 


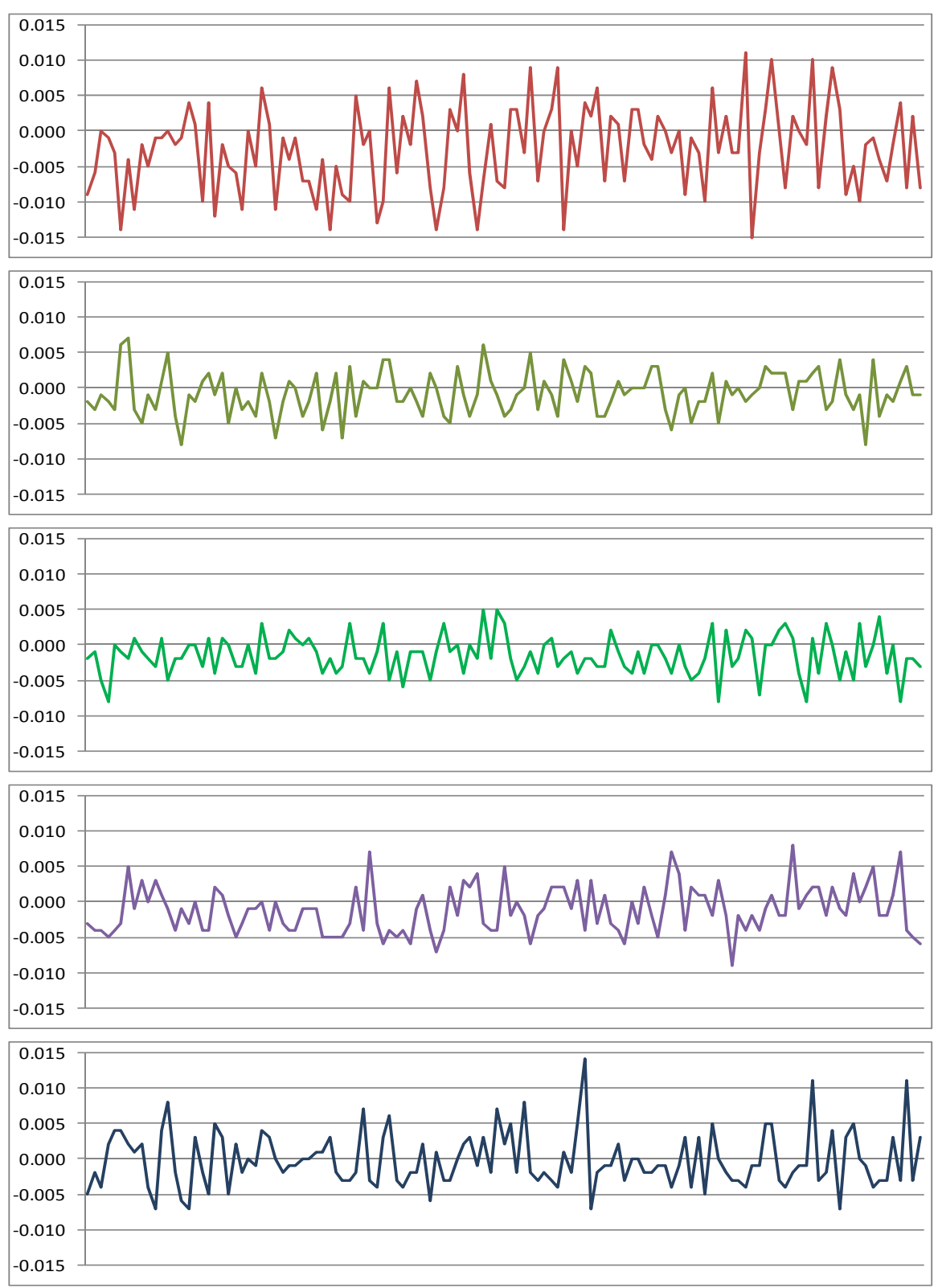

Fig. 5. The spread of measurement of the inclination angle 


\subsection{The field test}

A mobile antenna tower shown in Figure 6 was the study object. The both inclinometers and the weather station were installed on the tower, but because of the damage of one of the plugs there were obtained the results for only one inclinometer. These are shown in Figure 7.
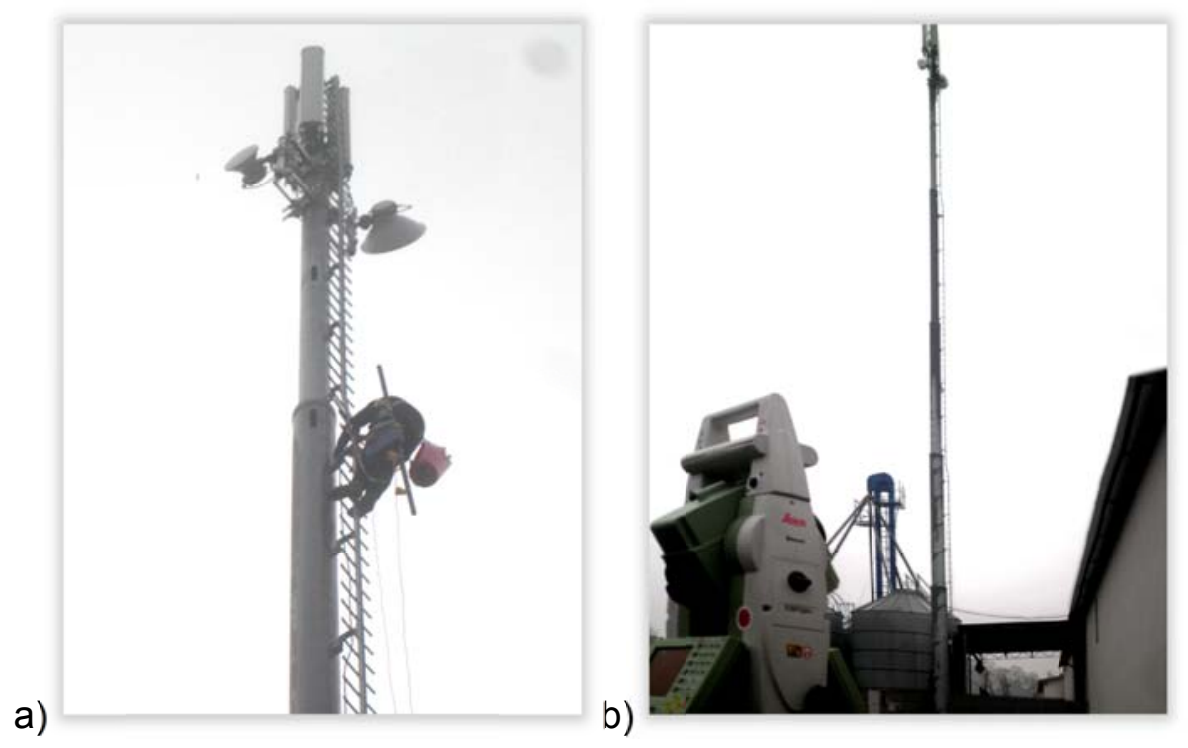

Fig. 6. Setting inclinometers (a) and deflection measurement of the mobile tower (b).

Before the main measurement the sensors were stabilized for two days. After the installation and before and after the start of data registration, the tower was measured using total station Leica TCRP1201+. It was found that at that time the tower leaned in excess of tachymeter accuracy (by surrounding tangents). Meanwhile the readings obtained from inclinometer were very interesting.

The evaluation of weather conditions showed that during the first day of observation the air temperature decreased from $10^{\circ} \mathrm{C}$ to $-3^{\circ} \mathrm{C}$. Next day, together with increasing temperature (up to $5^{\circ} \mathrm{C}$ ) the wind went up (to $15 \mathrm{~m} / \mathrm{s}$ ). During another night, along with sustained winds, the temperature dropped to $-8{ }^{\circ} \mathrm{C}$, and then - on the third day - it slightly increased (up to $-5^{\circ} \mathrm{C}$ ). At this time, the inclinometer vibrations moved from stabilized phase in the state of more than $\pm 0.1^{\circ}$. This quite big change occurred together with increasing wind speed (over $5 \mathrm{~m} / \mathrm{s}$ ). As a result, there was no change in inclination of the tower, but there was constant vibration - the tower or inclinometer. Because of no further observations this problem will be continued. Therefore, the tests were completed at this stage. 

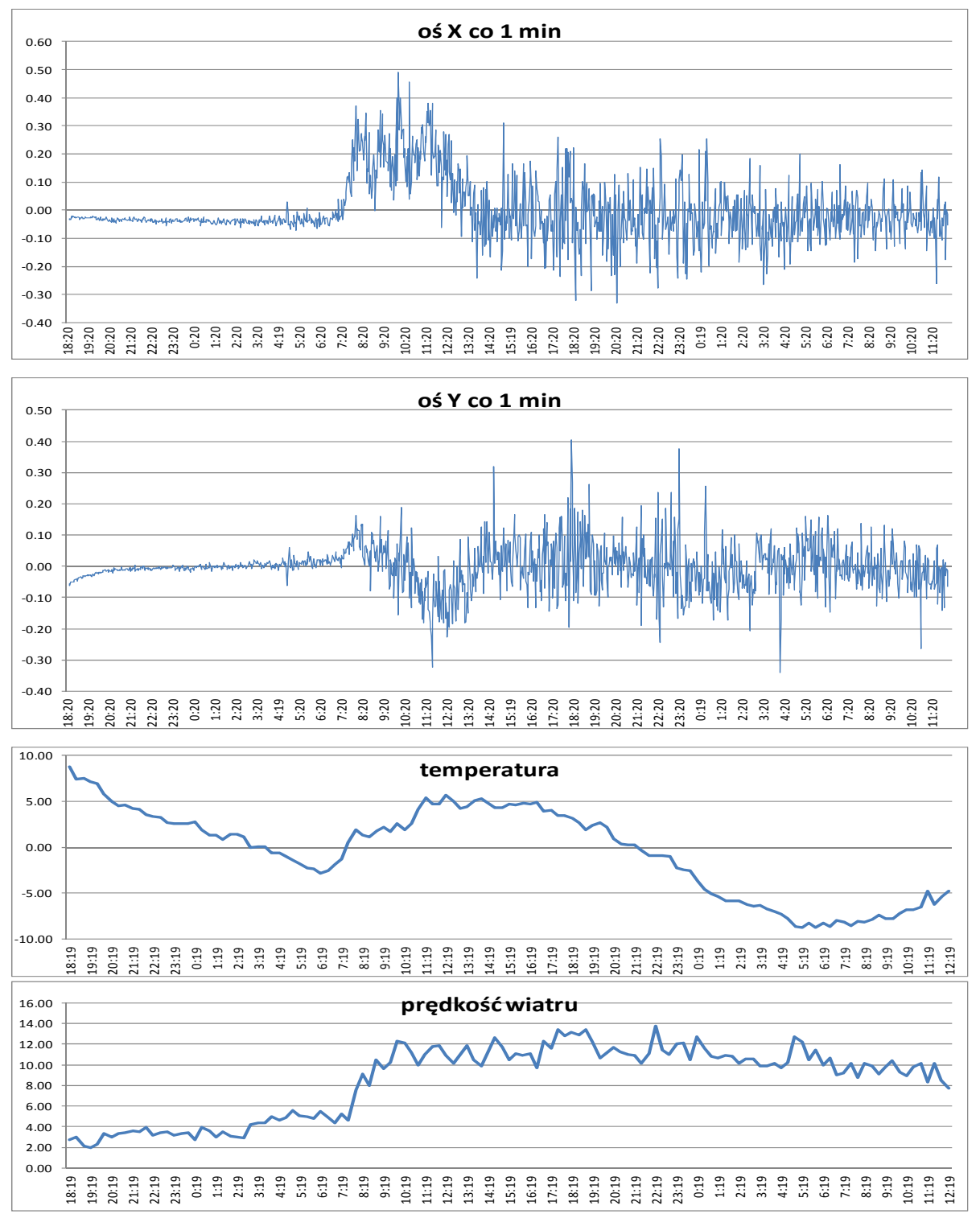

Fig. 7. Deflection readings in the directions of both axes $(x, y)$ and the results of measuring the temperature and wind speed.

\section{Summary and Conclusions}

As a result of the research it seems necessary to buy more sensors just like the Figure 2 shows. It is also necessary to carry out more tests with bigger representation of the appliances. For this purpose, it is undertaken:

1. The design and implementation of counting device (CZ1) and a local base station (LSB1) with wired connections;

2. Testing wireless (Internet) LSB database with the calculation data center;

3. Understanding and implementing other functions of AGS inclinometer;

4. Cooperation with the producers to explore the equipment and to undertake experiments for sensor rune reduction;

5. Testing inclinometer in various weather conditions, the development of the correction algorithm;

6. Application usage - Further measurements of mobile towers and bridge load testing. 
The above given results will be the topic of further publications. Now some conclusions can be drawn about this type of inclinometer. They are as follows:

1. POSITAL FRABA AGS15 inclinometer is an interesting object of study and has a potential utility for practical applications in the monitoring of engineering and geometrical structures;

2. This and other new electronic sensors should be an interesting tool for surveying engineering to develop the hardware and calculation units;

3. The own development of instrumentation sensors is a good way to raise skills and scientific growth,

4. The experience in obtaining reliable data should be combined with an effort of interpretation matters, undertaken by specialists in the field of structure and/or geotechnics.

\section{Acknowledgement}

This publication was developed as part of the research project no 12-261/DS/2012 funded by the Ministry of Science and Higher Education.

\section{References}

Álvarez-Vigil, A.E., González-Nicieza, C., López Gayarre, F. \& Álvarez-Fernández, M.I. (2010). Forensic analysis of the evolution of damages to buildings constructed in a mining area. Engineering Failure Analysis 17(4), June 2010, pp. 938-960.

Arnoso, J., Montesinos, F. G., Benavent, M. \& Vélez, E. J. (2012). The 2011 volcanic crisis at El Hierro (Canary Islands): monitoring ground deformation through tiltmeter and gravimetric observations. EGU General Assembly 2012, held 22-27 April, 2012 in Vienna, Austria., p. 5373.

Burdet, O.L. \& Zanella, J.-L., (2000). Automatic monitoring of bridges using electronic inclinometers. 16th Congress of IABSE, Lucerne, 2000.

Burdet, O.L. \& Zanella, J.-L., (2002). Automatic monitoring of the Riddes bridges using electronic inclinometers. First International Conference on Bridge Maintenance, Safety and Management IABMAS, Barcelona, 2002.

Hou, X., Yang, X. \& Huang, Q. (2005). Using Inclinometers to Measure Bridge Deflection. J. Bridge Eng., 10(5), pp. 564-569.

Milev, A., Share, P., Durrheim, R., Naoi, M., Nakatani, M., Yabe, Y. \& Ogasawara, H., (2013). Joint interpretation of high-precision tilt data and mining induced seismic events recorded underground in deep level gold mine in South Africa. EGU General Assembly 2013, held 7-12 April, 2013 in Vienna, Austria, p. 663.

Rohrmann, R. G., Thöns, S. \& Rücker, W., (2010). Integrated monitoring of offshore wind turbines - requirements, concepts and experiences. Structure and Infrastructure Engineering, 6(5), pp. 575-591.

Sherman, C. S., Magliocco, M. \& Glaser, S. D., (2011). Developing a Rock Mass Tilt And Seismic Observatory at DUSEL. 45th U.S. Rock Mechanics / Geomechanics Symposium, June 26-29, 2011, San Francisco, California. 
So-Keul, Ch., Dong-Woo, R., Won-II, J. \& Hyung-Sik Y., (2010). Characterization of Complete Radial Displacement of Tunnel Using a Horizontal Inclinometer. Geosystem Engineering, 13(2), pp. 77-82.

Wyczałek, I., Wyczałek, M. \& Nowak R., (2013). Badania porównawcze i integracja pomiarów pochyleń z pomiarami tachimetrycznymi. Archiwum Instytutu Inżynierii Lądowej, 15, pp. 157-168.

Yun Wu \& Yijin Wu, (2013). Study on Automatic Safety Monitoring and Management System of Tailings Reservoir. Advanced Materials Research, 663, pp. 1043-1048.

\section{Authors:}

Ireneusz Wyczałek ${ }^{1)}$, Ph.D. hab., Ireneusz.Wyczalek@put.poznan.pl

Artur Plichta ${ }^{1)}$, Ph.D., Artur.Plichta@put.poznan.pl

Michał Wyczałek ${ }^{1)}$, Msc, Michal.Wyczalek@put.poznan.pl

1) Poznan University of Technology, Institute of Civil Engineering

60-965 Poznań, ul. Piotrowo 5, Poland 